DIW BERLIN

Discussion

Papers

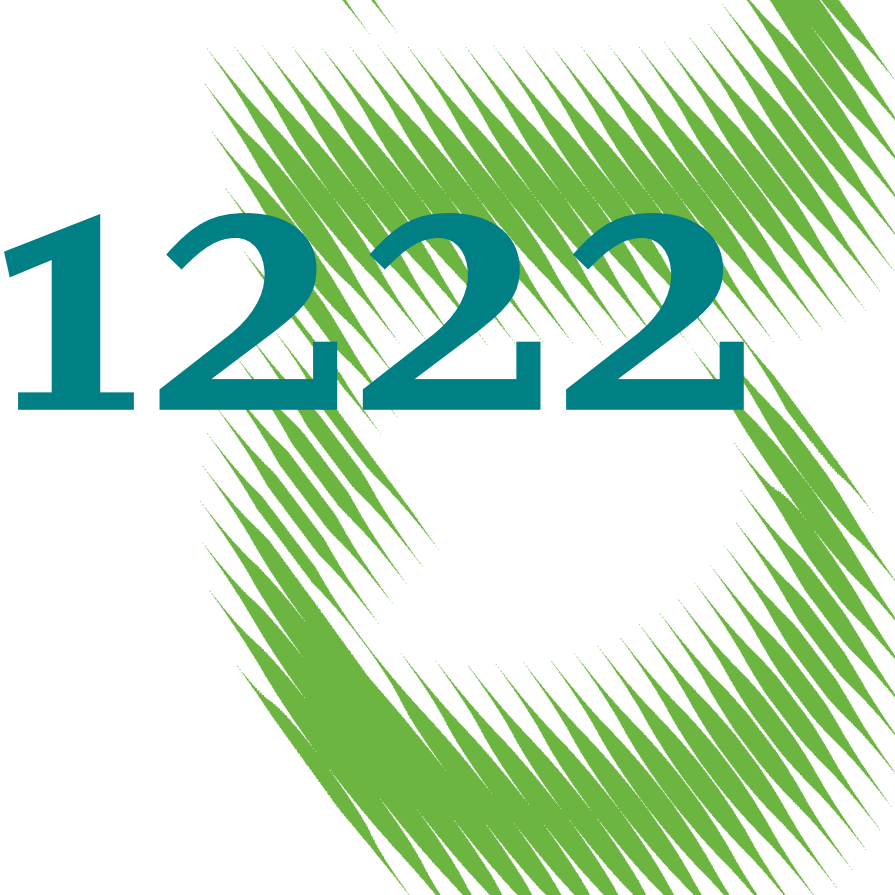

Marginal Employment, Unemployment Duration and Job Match Quality 
Opinions expressed in this paper are those of the author(s) and do not necessarily reflect views of the institute.

IMPRESSUM

(C) DIW Berlin, 2012

DIW Berlin

German Institute for Economic Research

Mohrenstr. 58

10117 Berlin

Tel. $+49(30) 89789-0$

Fax +49 (30) $89789-200$

http://www.diw.de

ISSN print edition $1433-0210$

ISSN electronic edition 1619-4535

Papers can be downloaded free of charge from the DIW Berlin website:

http://www.diw.de/discussionpapers

Discussion Papers of DIW Berlin are indexed in RePEc and SSRN:

http://ideas.repec.org/s/diw/diwwpp.html

http://www.ssrn.com/link/DIW-Berlin-German-Inst-Econ-Res.html 


\title{
Marginal Employment, Unemployment Duration and Job Match Quality
}

\author{
Marco Caliendo* Steffen Künn ${ }^{\dagger}$ \\ Arne Uhlendorff ${ }^{\ddagger}$
}

\author{
April 17, 2012
}

\begin{abstract}
In some countries including Germany unemployed workers can increase their income during job search by taking up "marginal employment" up to a threshold without any deduction from their benefits. Marginal employment can be considered as a wage subsidy as it lowers labour costs for firms owing to reduced social security contributions, and increases work incentives due to higher net earnings. Additional earnings during unemployment might lead to higher reservation wages prolonging the duration of unemployment, yet also giving unemployed individuals more time to search for better and more stable jobs. Furthermore, marginal employment might lower human capital deterioration and raise the job arrival rate due to network effects. To evaluate the impact of marginal employment on unemployment duration and subsequent job quality, we consider a sample of fresh entries into unemployment. Our results suggest that marginal employment leads to more stable post-unemployment jobs, has no impact on wages, and increases the job-finding probability if it is related to previous sectoral experience of the unemployed worker. We find evidence for time-varying treatment effects: whilst there is no significant impact during the first twelve months of unemployment, job finding probabilities increase after one year and the impact on job stability is stronger if the jobs are taken up later within the unemployment spell.
\end{abstract}

Keywords: marginal employment, unemployment duration, job search, JEL: $\quad$ J64, C41, C33

${ }^{*}$ University of Potsdam, IZA Bonn, DIW Berlin, IAB Nuremberg, Germany. Corresponding adress: University of Potsdam, Chair of Empirical Economics, August-Bebel-Str. 89, 14482 Potsdam, Germany. Phone: +49 331977 3225, Fax: +49 331977 3210, e-Mail: caliendo@uni-potsdam.de.

†IZA Bonn, Germany; University of Potsdam, Germany; e-Mail: kuenn@iza.org.

${ }^{\ddagger}$ University Mannheim, IZA Bonn, DIW Berlin, IAB Nuremberg; e-Mail: uhlendorff@uni-mannheim.de.

We thank Gerard van den Berg, Bo Honore, Bernd Fitzenberger, Ralf Wilke and seminar participants at the Berlin Network of Labour Market Research (BeNA), the University of Freiburg, the Paris School of Economics (PSE) and at the Royal Economic Society 2012 Annual Conference for helpful discussions and comments and Pia Schauerte for excellent research assistance. Marco Caliendo and Arne Uhlendorff thank the German Research Foundation (DFG) for financial support of the project CA 829/1-1. The Institute for Employment Research (IAB) in Nuremberg kindly gave us permission to use the administrative data. 



\section{Introduction}

Unemployment insurance (UI) systems provide benefit payments for unemployed job seekers. The amount of benefits usually depends on previous earnings and declines in accordance with the elapsed unemployment duration. Many studies have shown that more generous benefit schemes correspond with longer unemployment durations, while the empirical evidence of benefit generosity on job match quality is rather mixed and only some studies find positive impacts on post unemployment outcomes. ${ }^{1}$ In general, UI systems have to strike a balance between the insurance component and the aim of providing the opportunity to search for suitable job matches on the one hand and disincentive effects and moral hazard on the other hand.

Besides a decreasing profile of benefit payments, different strategies exist to increase the outflow probability from unemployment to employment, and to avoid long spells of unemployment. Such strategies comprise active labour market policies (ALMP) including training programs, wage subsidies, public employment measures, job search assistance and monitoring schemes (see Card, Kluve, and Weber, 2010; Kluve, 2010, for recent overviews of the effectiveness of these program types). In some countries such as Germany and Austria, the UI system is characterized by an additional feature: unemployed workers are allowed to work for some hours during their job search by taking up "marginal employment". This is defined as employment below a certain income threshold with reduced social security contributions (SSC). The main objective of marginal employment (known as "mini-job" in Germany) is to stimulate labour market flexibility in the low wage sector by increasing the attractiveness of those employment schemes to both firms and employees. Reduced social security contributions lead to lower labour costs for firms and higher work incentives resulting from the higher net income for individuals with low earnings. Although marginal employment does not legally belong within active labour market policy programs in Germany, from an economic perspective it is comparable to a wage subsidy. Marginal employment is used by a wide range of labour market groups. This includes individuals with high labour supply elasticities such as women, employed individuals who use it as a secondary job and unemployed individuals. Taking up marginal employment is attractive for unemployed individuals because they are allowed to keep a certain amount of additional earnings without any benefit reduction and might interact with participation probabilities in other measures of ALMP.

The expected effects of such a policy are ambiguous. On the one hand, marginal employment might increase the probability of taking up a regular job because it may lower human capital deterioration. Moreover, it may be used as a positive screening device or probation period by potential employers before offering a regular job and may increase the probability of receiving job offers due to network effects. However, on the other hand, the additional income should increase the reservation wage for taking up a regular job, which should prolong the unemployment duration. These effects may have an impact on both, the unemployment duration and the job match quality. For example, the increased

\footnotetext{
${ }^{1}$ For example Belzil (2001), Tatsiramos (2009) and Caliendo, Tatsiramos, and Uhlendorff (2009) find evidence for positive impacts while van Ours and Vodopivec (2008) and Card, Chetty, and Weber (2007) find no impact of the generosity of unemployment benefits on job quality.
} 
income due to marginal employment may allow the unemployed to wait for a better and more stable job, which could decrease the risk of re-entering unemployment. Hence, the overall impact of entering marginal employment on subsequent employment outcomes is theoretically ambiguous. It is the aim of this paper to empirically assess the overall impact of entering marginal employment on the unemployment duration and subsequent job quality of unemployed individuals.

Comparable to the German setting, unemployment insurance systems in Finland and Denmark allow the unemployed workers to take up a part-time job whilst in receipt of unemployment benefits, if they still search for a full-time job. Kyyrä (2010) applies a "timing of events" approach and finds evidence for positive effects on the transition rate to regular jobs for Finland, while Kyyrä, Parrotta, and Rosholm (2009) find heterogeneous effects on the expected unemployment duration for Denmark. Both studies do not take post unemployment outcomes into account. However, to evaluate the effectiveness of this kind of policy it is important to know whether taking up a part-time job or marginal employment during unemployment has an impact on the subsequent job quality and whether for example this reduces the probability of re-entering unemployment.

In this paper we take into account the dynamic selection of unemployed job seekers into marginal employment by applying the "timing of events approach" following Abbring and van den Berg (2003). This approach allows to control for selection into treatment based on both observed and unobserved characteristics. One central assumption of this approach is the no-anticipation assumption, which implies that individuals do not know exactly when a treatment - in this case entering marginal employment - will take place. ${ }^{2}$ Since the unemployed workers have to search for a mini-job, with the job finding probability dependent on the job offer arrival rate and the probability that the characteristics of the mini-job are acceptable, it seems very plausible that the event of entering the treatment is - similar to the transition to a regular job - not deterministic. We additionally evaluate the treatment effect on the job match quality, i.e. we extend the model by estimating the duration of subsequent employment spells and a wage equation for the initial wage. ${ }^{3}$ This framework furthermore allows to analyze effect heterogeneity with respect to observed characteristics such as age, skill level and the previous working sector, and to investigate whether the treatment effect varies with the elapsed unemployment duration.

Our analysis is based on an inflow sample of male workers into unemployment in West Germany in 2001. We observe labour market states of individuals for three years after entering unemployment, and our dataset includes daily wages of employed workers, detailed sectoral information about marginal and regular employment and a firm identifier which allows to investigate at least at a descriptive level whether individuals find a regular job in the same firm in which they have a mini-job.

Our results suggest that having a mini-job does not have any effect on the probability of finding a regular job within the first twelve months of unemployment. However, we find a significantly positive impact on the outflow probability for long-term unemployed

\footnotetext{
${ }^{2}$ It is important to note that this does not imply that the individuals do not know the probability distribution of future events conditional on observable and unobservable characteristics.

${ }^{3}$ For similar approaches in the context of sanction effects see Arni, Lalive, and van Ours (2012) and van den Berg and Vikström (2009).
} 
workers. Moreover, the jobs taken up by job seekers who entered a mini-job during their unemployment spell are more stable compared with jobs found by the non-treated individuals. These effects are stronger if the jobs are taken up later in the unemployment spell. We do not find any time-varying effects of taking up marginal employment on wages, but find some evidence for effect heterogeneity with respect to observable characteristics: more skilled individuals and individuals who are not working in the construction sector appear to have slightly lower wages if they have taken up a mini-job during unemployment, while a higher local unemployment rate correlates with lower wages for these workers. We find a significantly positive impact on the transition probability to regular employment if the mini-job is in the same sector as the previous regular job.

The paper is organized as follows: Section 2 describes the institutional background and surveys relevant previous research. Section 3 presents the data and descriptive statistics. Section 4 describes the econometric approach. The results of the empirical analysis are presented in Section 5, and Section 6 concludes.

\section{Institutional Background and Related Literature}

\subsection{Institutional Settings}

Marginal employment in Germany is defined as employment below a certain income level or as temporary employment for a fixed period, and is subject to reduced social security contributions. For 2010 the Federal Employment Agency reports about 7.3 million "marginal jobs", where around two-thirds of these jobs are held by individuals who do not have a regular regular job (including unemployed workers). The idea of marginal employment was primarily developed in the 1960's - a period in which labour demand exceeded its supply - as an attempt to increase work incentives for groups with traditionally low labour force participation, including students and housewives/-men, etc. At this time the German social security funds were well balanced, so policy makers decided to exempt low-income jobs from SSC to increase the attractiveness of such jobs (cf. Rudolph, 1999).

In the subsequent period marginal employment has been subject to several reforms; however we restrict the discussion to the parts which are relevant for our observation period of 2001 to 2004. The first main reform took place in April 1999, with the total exemption from SSC abolished as a response to firms substituting regular employment with marginal employment to avoid higher SSC in the late 1990s. Since then marginal employment was restricted to a maximum of $€ 325$ per month, combined with a working time restriction of 15 hours per week, and temporary employment contracts were restricted to a maximum of two months or 50 working days per year. While employees have been exempted from social security contributions, employers paid only a fixed rate of $22 \%$.

With the reform in April 2003 - known as the "mini-job" reform - the attractiveness of marginal employment was renewed in order to increase labour market flexibility within the low wage sector. Therefore, the income threshold increased from $€ 325$ to $€ 400$ per month, the working time restriction of 15 hours per week was abolished, and the SSC paid by the employer increased slightly to $23 \%$. While marginal employment as a secondary job 
was fully subject to SSC and taxes before April 2003, the reform exempted one secondary mini-job from both SSC and taxes for the employee.

Given our focus on the effect of taking up a mini-job during unemployment, we present a brief overview of the German unemployment insurance system. During our observation period from 2001 to 2004 the unemployment insurance system was characterized by two pillars: the unemployment benefits ("Arbeitslosengeld") and means-tested unemployment assistance ("Arbeitslosenhilfe"). Individuals were eligible for unemployment benefits if they were regularly employed subject to social security contributions for at least 12 months within the last three years. The benefit level relates to previous average earnings with a replacement rate of $60 \%$ (67\% with children living in the household) of net earnings whereby earnings are capped by the social security contribution assessment ceiling. ${ }^{4}$ After the unemployment benefit entitlement expired - which ranges in that period from six to 32 months depending on age and the time spent in employment in the previous seven years individuals become eligible for means-tested unemployment assistance given they are still searching for a job, with a decreased replacement rate of $53 \%$ ( $57 \%$ with children). For a detailed overview of the unemployment insurance system in Germany see e.g. Konle-Seidl, Eichhorst, and Grienberger-Zingerle (2010). In addition to these transfer payments, the unemployed in Germany are allowed to earn additional income through employment. This possibility is intended to encourage the unemployed to take up marginal employment in order to stay attached to the labour market. Therefore, recipients of unemployment benefit are allowed to keep $€ 165 /$ month of additional earnings without suffering a reduction in unemployment benefits as long as their working time does not exceed 15 hours per week. Earnings above this threshold are fully withdrawn.

It is important to note that the mini-job reform in 2003 had no impact on the situation of unemployed workers. The conditions for additional earnings during the receipt of unemployment benefits, i.e., the exemption rate of $€ 165$ and working time restrictions of 15 hours per week, remained unchanged across the reform in 2003. Caliendo and Wrohlich (2010) show that only marginal employment as a secondary job and the labour supply of students increased significantly due to the 2003 reform. They do not find any evidence for a significant impact on the unemployed, which is plausible since the incentive for the unemployed to take up marginal employment did not change within this reform. Conversely, incentives for individuals in regular employment increased remarkably because income from one single mini-job is totally exempted from social security contributions and taxation. However, this is not part of our analysis and does not influence our results.

\subsection{Related Literature}

There exists a number of empirical studies investigating "stepping stone effects" of different employment types to enter regular jobs. For example, Cockx and Picchio (2011) analyze the impact of short-term jobs on subsequent employment outcomes in Belgium based on a multivariate duration model and find evidence for short-term jobs representing a spring-

\footnotetext{
${ }^{4}$ The social security contribution assessment ceiling is the maximum amount of earnings which is eligible to social security contribution. In 2001 it amounted to gross earnings of 4,450€/month and in 2004 to $5,150 € /$ month in West Germany.
} 
board to long-term jobs. An earlier example for a multivariate duration model in the stepping stone literature is van den Berg, Holm, and van Ours (2002), who find that a job as a medical assistant increases the probability of becoming a medical specialist in the Netherlands. Zijl, van den Berg, and Heyma (2011) employ a similar approach and find that temporary jobs shorten the unemployment duration in the Netherlands but do not lead to a higher proportion of unemployed workers having regular jobs. In Finland, unemployed workers are allowed to take up a part-time or a short full-time job whilst receiving unemployment benefit if they continue searching for a full-time job. Kyyrä (2010) applies a timing of events approach and his results suggest that this might have positive effects on the transition rate to regular jobs. He finds evidence for an increasing impact of taking up a short full-time job over the unemployment duration, i.e., for those who take up a short full-time job shortly after entering unemployment the treatment effect does not differ significantly from zero, but it becomes stronger with the elapsed unemployment duration. For part-time jobs he does not find evidence for effect heterogeneity with respect to the elapsed unemployment duration. Within a similar institutional setting in Denmark Kyyrä, Parrotta, and Rosholm (2009) find heterogenous effects of taking up a part-time job during job search on the expected unemployment duration, for example with respect to age, sex and marital status. Neither of the two studies take post-unemployment outcomes into consideration.

There exist two studies investigating the effects of marginal employment on subsequent employment outcomes. Freier and Steiner (2008) analyze the effect of marginal employment as a stepping stone to regular employment in Germany. They find that marginal employment leads to a reduction in future unemployment and slightly increases cumulated earnings. However, they do not find positive effects in terms of time spent in regular employment. In a study for Austria, Böheim and Weber (2011) find that marginally employed workers experience less frequent regular employment, more unemployment and lower wages compared to non-participants. Both studies apply a static propensity score matching approach and rely on the conditional independence assumption which implies that conditional on observable characteristics entering a mini-job is not correlated with unobserved characteristics which have an impact on later outcomes.

\section{Data and descriptive statistics}

\subsection{Dataset and sample definition}

Our analysis is based on data from the administrative part of the IZA Evaluation Dataset ${ }^{5}$. This dataset is based on the Integrated Employment Biographies (IEB) by the Institute for Employment Research (IAB) and consists of a random draw of unemployment entries between 2001 and 2008. The IEB consists of different sources, e.g., employment history, benefit recipient history, training participant history and job search history and therefore contains detailed information on employment subject to social security contributions, un-

\footnotetext{
${ }^{5}$ For a detailed description of the IZA Evaluation Dataset see Caliendo, Falk, Kaiser, Schneider, Uhlendorff, van den Berg, and Zimmermann (2011).
} 
employment and participation in active labour market policy including wages and transfer payments. The data additionally include a broad range of socio-economic characteristic including education, family status and health restrictions. The data do not contain information about the working hours and periods in self-employment, working as a civil servant, or spent in inactivity. From this data we draw a random sample of inflows into unemployment in 2001. The unemployment spell must last at least two weeks and prior to this unemployment entry the individuals have to be employed subject to social security contributions for a minimum duration of three months to ensure that we have a "real" inflow sample into unemployment. Moreover, we exclude individuals who had a mini-job during the three months before entering unemployment because we want to model the inflow into the treatment. We restrict our observation period from 2001 to 2004, since in a major reform of the German UI system was introduced in 2005.

Our sample is based on male individuals in West Germany. We focus on males because nearly all men work full-time if they have a regular job. In contrast, part-time work is much more common among females (see e.g. Haan, 2010). This implies that in some cases it is difficult to distinguish between preferred part-time jobs and mini-jobs for women during job searches in our dataset. Furthermore, the high share of part-timers among women renders an evaluation of wages in the first job after leaving unemployment difficult as we do not observe working hours. Since East and West Germany still differ substantially in terms of economic and labour market indicators during our observation period, we exclude East Germany from the analysis. As we are interested in the transition to regular employment and subsequent job stability, the adverse labour market conditions in East Germany might have distorting effects, making results difficult to interpret and transfer to other countries. Moreover, the share of unemployed individuals entering public employment programs is clearly higher in East than West Germany. Therefore, focusing on men in West German leads to a relatively homogeneous estimation sample. Nevertheless, analysing differences between East and West Germany would be an interesting avenue for further research. We further restrict our sample to men aged between 25 and 55. The lower age restriction is motivated by the educational system, and the upper by the retirement schemes in Germany. Our final sample thus consists of 24,131 individuals out of which we randomly draw an estimation sample of 10,000 individuals to reduce the computational burden. We follow each individual for 36 months from entry into unemployment onwards. As in Germany most of employment spells start at the beginning of a month (and unemployment spells typically last until the end of a month), we construct discrete time spell data in which one month corresponds to one time unit.

In our dataset we define two mutually exclusive labour market states: unemployment and regular employment. Individuals who are either registered as unemployed at the Federal Employment Office (with or without benefit receipt) or participants of programs of the Active Labour Market Policy are defined as being unemployed. During unemployment individuals might take up a mini-job. Periods in which individuals take up marginal employment without having a parallel unemployment spell are not included in our sample and individuals with a mini-job as a secondary job are defined as being regularly employed, i.e. the secondary job is ignored. Regular employment is defined as employment subject 
to social security contributions. ${ }^{6}$ We exclude any periods without information for more than one month which allows us to attribute a spell to unemployment or employment and treat the corresponding spells as right-censored. ${ }^{7}$ This might be due to self-employment, employment as a civil servant, or not being available to the labour market. A further reason might be that individuals de-register as unemployment benefits elapse or are too low (compared to the administrative burden) yet still continue looking for a job. As our sample consists of prime-age men only, it is likely that individuals who are neither self-employed nor civil servants continue seeking a job independent of being registered as unemployed. Therefore, we examine the sensitivity of our results to this aspect in Section 5.3 and redefine uncovered periods as unemployment. This largely leads to longer unemployment spells and more individuals who take up a mini-job during our observation period.

\subsection{Descriptive statistics of transition processes}

Table 1 provides the number of spells per individual spent in unemployment, in unemployment with a transition to a mini-job, and employment within our observation window. ${ }^{8}$

\section{[INSERT TABLE 1 ABOUT HeRE]}

Due to the construction of our sample (inflows into unemployment) every individual has at least one unemployment spell. Almost half of all individuals have repeated unemployment spells and only a minority have five or more spells; in fact, 5,516 individuals have only a single unemployment spell, while 82 individuals have five or more. Around 8,500 individuals never take up a mini-job during unemployment, and for around 2,900 individuals we do not observe a transition to regular employment.

\section{[INSERT Figure 1 ABOUt HeRE]}

Figure 1 depicts the hazard rates for the transition from unemployment to regular employment, and the take-up rate of mini-jobs during unemployment. The probability of leaving unemployment for a regular job is first increasing and - after around five months - decreases with the elapsed unemployment duration. Compared to the transition from unemployment to employment the probability of entering a mini-job is rather low, and does not vary strongly according to the elapsed unemployment duration.

\subsection{Transitions to ALMP}

Starting from unemployment entry, different strategies exist to increase the outflow probability from unemployment. Besides a decreasing profile of benefit payments, one main strategy consist of assigning unemployed individuals to programs of active labour market policies, e.g., training programs, wage subsidies, public employment measures, job search

\footnotetext{
${ }^{6}$ To exclude low-income jobs, we determine a minimum income of $600 € /$ month and corresponding employment spells with an income below that threshold are right censored.

${ }^{7}$ In our sample $29.7 \%$ of individuals face right censored spells due to missing information.

${ }^{8} \mathrm{~A}$ spell is defined as a continuous period of time within the same state without an interruption, i.e., no transitions to other states.
} 
assistance and monitoring schemes. In addition to those measures, unemployed individuals in Germany face one additional feature: marginal employment. To assess the meaning of the different strategies for the unemployed, we follow individuals from unemployment entry onwards and consider the first transition to programs of ALMP or mini-jobs. Table A.1 shows respective shares within the estimation sample. Overall, it is visible that marginal employment is as important for unemployed individuals as programs of ALMP (see upper panel of Table A.1). For instance, $7.2 \%$ take up a mini-job while $4.9 \%$ and $9.3 \%$ are assigned to vocational and short-term training measures.

Table A.1 further shows in the lower panel that individuals with a mini-job face a higher probability to participate in ALMP compared to unemployed individuals without a mini-job. Although higher participation might be explained by longer unemployment spells among treated individuals and the negative selection into mini-jobs, i.e., unemployed individuals who take up a mini-job are on average lower educated and located in regions with poor labour market conditions (see Table 2 below), the positive correlation between having a mini-job and entering ALMP suggests that the effectiveness of marginal employment and programs of ALMP might interact.

To shed light on this issue, it is first of all required to know if marginal employment indeed has a significant impact on labour market outcomes. In this paper, we address this question and evaluate the impact of marginal employment on unemployment duration and subsequent job quality. Based on this evidence, future research should then shed some light on the interaction of marginal employment and measures like job search and training programs for unemployed workers.

\subsection{Differences in observable characteristics}

Table 2 provides descriptive statistics measured at the initial entry into unemployment in 2001. Results are depicted for the full and estimation sample, and in addition are separated by treatment status, i.e., those who take up a mini-job during the 36 months and those who do not.

\section{[INSERT TABLE 2 ABOUt HeRE]}

First of all, the sample reduction (due to computational reasons) introduces no selection bias as observable characteristics are almost equally distributed between the full and the estimation sample. Of the 10,000 drawn individuals, 1,507 take up a mini-job during unemployment within our observation window. Comparing both subgroups in column three and four suggests that the group of individuals who take up marginal employment are on average lower educated in terms of both schooling and professional training. For example, around $13.5 \%$ among the treated individuals have no schooling degree, while this share is only around $9 \%$ for the non-treated. More than $40 \%$ of the unemployed workers who take up a mini-job do not have any occupational degree. The corresponding share among the comparison group is less than $30 \%$. The sectoral distribution, the mean age and the family status is rather similar between treated and non-treated individuals, while individuals in regions with higher local unemployment rates and lower GDP per capita are more likely to 
enter a mini-job during unemployment. Local unemployment is measured on a quarterly basis, while the local GDP per capita is measured on a yearly basis. ${ }^{9}$

\subsection{Characteristics of mini-job spells}

To establish the extent mini-jobs serve as a stepping stone it is important to have more information on the mini-jobs themselves. ${ }^{10}$. In our data we have information about the sector in which individuals have regular jobs and mini-jobs. Table 3 displays the sectoral distribution of mini-jobs in our sample. Mini-jobs are primarily provided by the service and the construction sectors and this is similar among skilled and unskilled workers, although the share of unskilled workers taking up a mini-job in the service sector is larger $(50.4 \%)$ than the corresponding share among skilled individuals (41.4\%).

\section{[INSERT TABLE 3 ABOUT HERE]}

More interestingly, Table 4 and 5 depict a sectoral comparison of the mini-job with the previous and subsequent regular job, respectively. For instance, Table 4 shows that among all unemployed who take up a mini-job and previously worked in the construction sector, $75.2 \%$ have a mini-job in the same sector while the rest are marginally employed in a different sector. We observe two patterns in Table 4. First, we see that many individuals take up a mini-job in the same sector in which they worked before entering unemployment. Second, if workers change the sector, they usually take up mini-jobs in the service sector. Table 5 suggests a strong correlation between sectors for the mini-job and the subsequent regular job. For example, $82.4 \%$ of the individuals with a mini-job in the construction sector and for whom we observe a transition into a regular job find employment in the construction sector. These numbers indicate that the mini-jobs are related to the sectoral experience and skills of the unemployed workers, which suggests that they might be relevant for the job-finding probability, for example by lowering human capital deterioration, as a screening device for potential employers or by increasing the probability of getting job offers due to network effects.

\section{[INSERT TABLE 4 AND 5 ABOUt HeRE]}

Further to the finding that unemployed with a mini-job are likely to find regular employment in the same sector, in Table 6 we present the shares of treated individuals who find a regular job in the same firm in which they have been marginally employed. In the upper panel we consider all transitions to regular employment with a mini-job at any time before. In the lower panel we only take into account spells in which the unemployed worker was still marginally employed in the month of the exit from unemployment to employment, i.e. the individual has not left the mini-job before finding a new regular job. A large share of marginal employed individuals find a regular job within the same firm $(45 \%)$, which suggests that mini-jobs are in some cases utilized as a probation period.

\footnotetext{
${ }^{9}$ Both the unemployment rate and the GDP are measured on an employment agency district level. In total, there are 178 employment agency districts in Germany.

${ }^{10}$ Mini-jobs in our sample have a mean (median) duration of 4.7 (3) months
} 
The share of transitions within the same firm is with $52 \%$ higher in the first 12 months of unemployment than the corresponding share after one year of unemployment (30.3\%). Within the group of individuals who are holding a mini-job in the month that they find a new job, the corresponding shares are slightly higher (60.0\% and $39.3 \%$, respectively).

\section{[INSERT TABLE 6 ABOUT HERE]}

As discussed in the chapter on the institutional background, unemployed workers are allowed to earn up to $165 € /$ month without suffering a reduction in transfer payments. This implies that the average treated individual in our sample can increase his income during unemployment by around $23 \%$. Figure 2 depicts the income distribution of mini-jobs during unemployment and it can be seen that indeed $50 \%$ earn $164 € /$ month or less. However, there is still a large fraction of job seekers who earn more than threshold amount. These higher earnings might be explained by labour demand side restriction, i.e., the offered jobs do not always have the exact number of working hours which would result in $165 € /$ month. This supports the idea that there exist search frictions in the segment of the mini-jobs.

\section{[InsERT Figure 2 ABOUt HeRE]}

\section{Empirical Model}

We are interested in the causal impact of taking up a mini-job on two outcomes, the unemployment duration and the job match quality. Individuals are defined to be treated if they enter a mini-job in month $t$ of the unemployment spell from the corresponding month $t$ onwards. This implies that individuals who have a mini-job for some time during unemployment and leave this marginal employment before they find a regular job are still defined to be "treated".

In this section we start with the presentation of a bivariate duration model for the duration until leaving unemployment for a job and the duration until the treatment, which is entering marginal employment, following the "timing of events" approach (Abbring and van den Berg, 2003). ${ }^{11}$ In a next step we extend this by incorporating the job match quality similar to van den Berg and Vikström (2009).

As depicted in Table 1, our dataset contains multiple observations for some individuals, which facilitates the identification and estimation of the joint distribution of the unobserved heterogeneity variables (see e.g. Honore, 1993). Moreover, our dataset includes time-varying variables such as the local unemployment rate. Eberwein, Ham, and LaLonde (1997) and Gaure, Roed, and Zhang (2007) emphasize that time-varying covariates provide exclusion restrictions because past values affect current transition probabilities only through the selection process, i.e. time-varying covariates provide a more robust source of identification than time-invariant covariates. These features of the dataset imply that identification does not solely rely on the functional form of the model.

\footnotetext{
${ }^{11}$ We estimate a discrete time duration model. Abbring and van den Berg (2003) provide a proof for continuous time models. For identification in dynamic discrete models see Heckman and Navarro (2007).
} 


\subsection{Durations until employment and until treatment}

As we observe an inflow sample into unemployment, we do not have to take the initial condition problem into account (Heckman, 1981), because every individual is initially unemployed. We observe labour market states in discrete time and assume that all individual differences in the probability of leaving unemployment for a job in period $t$ can be characterized by observed characteristics $x$, unobserved characteristics $V_{u}$, and a treatment effect if a mini-job has been taken up before or at the discrete period $t$. Similarly, we assume that all individual differences in the probability of being treated in period $t$ can be characterized by observable characteristics $x$ and unobserved characteristics $V_{m}$. Given these assumptions the probability of leaving unemployment for a job $\theta_{u}(t)$ and the probability of taking up marginal employment $\theta_{m}(t)$ can be expressed by complementary log $\log$ specifications:

$$
\begin{aligned}
\theta_{u}\left(t \mid x, V_{u}, t_{m}\right) & =1-\exp \left(-\exp \left(\lambda_{t u}+x_{t}^{\prime} \beta_{u}+I\left(t \geq t_{m}\right) \delta_{u}+V_{u}\right)\right) \\
\theta_{m}\left(t \mid x, V_{m}\right) & =1-\exp \left(-\exp \left(\lambda_{t m}+x_{t}^{\prime} \beta_{m}+V_{m}\right)\right)
\end{aligned}
$$

$I(\cdot)$ takes on the value one if $t \geq t_{m}$ and $\delta_{u}$ is the effect of being treated on the probability of finding a job. We assume that the treatment does not affect the probability of leaving unemployment for a job before the moment of accepting the job. This assumption is referred to as the no-anticipation assumption and is very likely to hold in our application. The unemployed workers have to search for a mini-job and - similar to the transition to a regular job - the job-finding probability depends on the job offer arrival rate and the probability that the job characteristics are acceptable. This implies that the job finding process is stochastic. We assume that the unemployed workers do not know the exact timing of the treatment. However, they are allowed to know the probability distribution of future events conditional on observable and unobservable characteristics. Moreover, we assume that the unobserved heterogeneity components $V_{u}$ and $V_{m}$ are constant over time, i.e. across repeated spells of unemployed individuals, and that $V_{u}$ and $V_{m}$ are uncorrelated with observed characteristics $x$.

\subsection{Post-unemployment outcomes}

We measure the job match quality by the monthly wage and the probability of reentering unemployment. We allow both outcomes to depend on unobserved characteristics which might be correlated with the unobserved factors $V_{u}$ and $V_{m}$. In order to identify the causal impact of mini-jobs on realized wages, we assume that the unobserved heterogeneity and the causal effect have an additive impact on the mean log wage. We specify the following equation for the wage at the beginning of the new employment spell:

$$
\ln w=x_{t}^{\prime} \beta_{w}+I\left(t_{m} \leq t_{u}\right) \delta_{w}+t_{u} \eta_{w}+V_{w}+\varepsilon_{w}
$$

The treatment effect is given by $\delta_{w}, V_{w}$ is the unobserved heterogeneity which is assumed to be constant across repeated spells, and $\varepsilon_{w}$ is assumed to be normally distributed with mean zero and unknown variance $\sigma_{w}$. In addition, we allow the log wage to vary with respect to the previous unemployment duration $t_{u}$. 
Similarly to the duration of unemployment we specify a duration of employment, described by the probability of leaving employment and reentering unemployment in period $t$. We assume that all individual differences in the probability of reentering unemployment in $t$ can be characterized by observed characteristics $x$, unobserved characteristics $V_{e}$ and a treatment effect $\delta_{e}$ if a mini-job has been taken up in the previous unemployment spell. The probability of leaving employment in period $t$ is given by:

$$
\theta_{e}\left(t \mid x, V_{e}, t_{u}, t_{m}\right)=1-\exp \left(-\exp \left(\lambda_{t e}+x_{t}^{\prime} \beta_{e}+I\left(t_{m} \leq t_{u}\right) \delta_{e}+t_{u} \eta_{e}+V_{e}\right)\right)
$$

Similarly to the wage equation we allow $\theta_{e}$ to vary with respect to the previous unemployment duration $t_{u}$. In the empirical specification we include a linear and a quadratic term reflecting the previous unemployment duration in a flexible way. $V_{e}$ is constant over time and uncorrelated with observed characteristics $x$. However, $V_{e}$ and $V_{w}$ might be correlated with the treatment indicator and the previous unemployment duration, which captures the dynamic selection into job matches.

\subsection{Distribution of unobserved heterogeneity}

We specify the distribution of unobserved heterogeneity $G$ to have a discrete support with $P$ support points. In order to ensure that the corresponding probabilities are between zero and one and to sum to one, we use a multinomial logit parameterization of the class probabilities:

$$
\pi_{p}=\frac{\exp \left(\omega_{p}\right)}{\sum_{p=1}^{P} \exp \left(\omega_{p}\right)}, \quad p=1, \ldots, P, \quad \omega_{1}=0
$$

Each of the six components of the unobserved heterogeneity $V$ takes on a specific value at support point $p$, whereby for identification reasons the values are set to be zero for $p=1$. This implies that for a model with $P=2 G$ would be described by 5 parameters, for $P=3$ we estimate 10 parameters, etc. ${ }^{12}$ This approach allows for a flexible covariance matrix for the unobserved components. For a similar model for unobserved heterogeneity in the context of timing of events models see Crepon, Ferracci, Jolivet, and van den Berg (2010) and in the context of random coefficient models in the statistical literature see e.g. Aitkin (1999). Gaure, Roed, and Zhang (2007) provide Monte Carlo evidence that modeling selection based on unobservables by a flexible discrete distribution works well in the context of timing of events models. In the estimation we increase the number of support points until the model fit cannot be further improved by an additional support point, evaluated on the basis of the Akaike Criterion (AIC) and Bayesian Information Criterion (BIC).

\subsection{Likelihood function}

Given this setup, the likelihood contribution of an individual $i$ with one sequence $s$, i.e., one unemployment spell of length $t_{u}$ and one employment spell of length $t_{e}$, for given

\footnotetext{
${ }^{12}$ For $P=2$ we estimate the parameters $V_{u 2}, V_{m 2}, V_{e 2}, V_{w 2}, \omega_{2}$. For $P=3$ we estimate $V_{u 2}, V_{m 2}, V_{e 2}$, $V_{w 2}, \omega_{2}$ and $V_{u 3}, V_{m 3}, V_{e 3}, V_{w 3}, \omega_{3}$.
} 
unobserved and observed characteristics $V$ and $x$ is given by:

$$
\begin{aligned}
L_{i s}(x, V)= & \prod_{t=1}^{t_{m}}\left[1-\theta_{m}\left(t \mid x, V_{m}\right)\right]\left(\frac{\theta_{m}\left(t_{m} \mid x, V_{m}\right)}{1-\theta_{m}\left(t_{m} \mid x, V_{m}\right)}\right)^{\kappa_{m}} \\
& \prod_{t=1}^{t_{u}}\left[1-\theta_{u}\left(t \mid x, V_{u}, t_{m}\right)\right]\left(\frac{\theta_{u}\left(t_{u} \mid x, V_{u}, t_{m}\right)}{1-\theta_{u}\left(t_{u} \mid x, V_{u}, t_{m}\right)}\right)^{\kappa_{u}} \\
& \prod_{t=t_{u}+1}^{t_{u}+t_{e}}\left[1-\theta_{e}\left(t \mid x, V_{e}, t_{u}, t_{m}\right)\right]^{\kappa_{u}}\left(\frac{\theta_{e}\left(t_{e} \mid x, V_{e}, t_{u}, t_{m}\right)}{1-\theta_{e}\left(t_{e} \mid x, V_{e}, t_{u}, t_{m}\right)}\right)^{\kappa_{u} \kappa_{e}} \\
& \left(\frac{1}{\sqrt{2 \pi \sigma^{2}}} \exp \left(-\frac{\left(\ln w_{i}-\widehat{\ln w_{i}}\right)^{2}}{2 \sigma^{2}}\right)\right)^{\kappa_{u}}
\end{aligned}
$$

The indicators $\kappa_{m}, \kappa_{u}$ and $\kappa_{e}$ take on the value one if a transition to a mini-job, to regular employment or to unemployment, respectively, is observed and zero otherwise. $\ln w_{i}$ is the logarithm of the observed wage in our data - in case we observe a transition from unemployment to a regular job - and $\widehat{\ln w_{i}}$ corresponds to the predicted value based on the coefficients $\beta_{w}$. We observe multiple spells for some individuals in our dataset. Therefore, the likelihood contribution of an individual corresponds to the product of the likelihood contributions of $S$ sequences of unemployment and employment spells.

$$
L_{i}(x, V)=\prod_{s=1}^{S} L_{i s}(x, V)
$$

Since we do not know the unobserved characteristics for an individual $i$, the "unconditional" log-likelihood contribution corresponds to the weighted sum of the contributions corresponding to the $P$ points of support. The log-Likelihood function for the sample with $\mathrm{N}$ individuals is given by:

$$
\ln L=\sum_{i=1}^{N} \ln \sum_{p=1}^{P} \pi_{p} L_{i}(x, V(p))
$$

\section{Results}

We estimate the duration until finding a mini-job, the duration of unemployment, the duration of employment and the reemployment wage with jointly distributed unobserved heterogeneity. We estimate different empirical specifications of this model. Starting with a baseline model which allows for homogeneous treatment effects, in a second step we introduce effect heterogeneity with respect to selected observable characteristics. In a third step we estimate interaction effects of the treatment indicator with elapsed unemployment duration. Finally, we reestimate our model on a sample in which we re-define uncovered periods in the data as unemployment in order to test whether our results are robust with respect to this alternative specification of employment states. 


\subsection{Baseline results}

In Table 7 we report the treatment effects on different outcomes. We control for observable characteristics as reported in Table 2 and allow for flexible duration dependencies for the duration in unemployment, the duration until treatment and the employment duration. Moreover, we control for the quarter in which the corresponding spell starts and include time-varying dummy indicators for the current quarter to capture seasonal effects. ${ }^{13}$ Our final specification includes 9 mass points $(\mathrm{P}=9)$, i.e. we estimate 40 additional parameters for the distribution of unobserved characteristics compared to a model without unobserved heterogeneity. A further increase of the mass points does not lead to a better model fit, evaluated on the basis of the AIC and the BIC. The coefficients of the preferred model with unobserved heterogeneity are reported in the columns (2) for the unemployment duration, in column (4) for the employment duration and in column (6) for the wages in Table 7. Columns (1), (3) and (5) refer to a model without controlling for selection based on unobserved characteristics.

Commencing with column (1), we report the coefficient of the time-varying treatment dummy for the probability of leaving unemployment for a regular job. The parameter is positive and significantly different from zero. Once we control for unobserved heterogeneity in column (2), the treatment effect clearly decreases and is no longer significantly different from zero. This suggests that mini-jobs are neither stepping-stones to regular jobs, nor do they lead to longer spells of unemployment.

\section{[INSERT TABLE 7 ABOUt HeRE]}

Column (3) shows that we do not find any effect of the mini-job dummy on employment stability in a model without unobserved heterogeneity. However, once we control for selection, the estimated parameter suggests that treated individuals re-enter unemployment with a lower probability than individuals who have not been treated (column 4). Moreover, these individuals have nearly the same wages compared to the non-treated individuals when they take up a regular job (column 6). In the "naive" model without controlling for dynamic selection based on unobserved characteristics we estimate a significantly negative impact of mini-jobs on wages (column 5). These results underline the importance of controlling for dynamic selection. The correlations between the different components of unobserved heterogeneity are all statistically significant (see Table A.2).

Overall, the baseline model suggests that mini-jobs are not increasing the outflow probability from unemployment and do not lead to higher paid jobs, but the treated individuals end up in more stable employment spells.

\section{$5.2 \quad$ Heterogenous treatment effects}

To investigate effect heterogeneity we interact the treatment dummy with selected observable characteristics. These characteristics include individuals' age, dummy variables

\footnotetext{
${ }^{13}$ The complete set of coefficients including the distribution of the unobserved heterogeneity are available on request. The correlations between the different components of the unobserved heterogeneity are reported in the Appendix in Table A.2.
} 
for being unskilled and for having worked in the construction sector in the last regular job, and the local unemployment rate. Additionally, we include a dummy variable indicating whether or not the mini-job is in the same sector as the previous regular job. We distinguish between five sectors: construction, production, wholesale/retail, private sector services, and others. We particularly investigate the treatment effect for the construction sector, because this sector is characterized by strong seasonal employment patterns which might imply a specific role of mini-jobs for periods of unemployment. To allow for nonlinear effects, we include the logarithm of age. The estimation results are reported in Table 8. The reference person is an individual of mean age located in a region with the mean local unemployment rate, not working in the construction sector, not being unskilled and having a mini-job in a different sector than the previous job. The coefficient of the treatment dummy reflects the treatment for this reference person, and the coefficients of the interaction terms capture the heterogenous effects for example with respect to the local unemployment rate or age.

\section{[INSERT TABLE 8 ABOUT HERE]}

We do not find evidence for effect heterogeneity for the transition probability from unemployment to regular employment with respect to age, skill level, whether or not the unemployed has worked in the construction sector before entering unemployment, and the local unemployment rate. However, we find a significantly positive impact on the transition probability to regular employment, if the mini-job is in the same sector as the previous job. By contrast, having a mini-job in a different sector increases the income during unemployment, yet does not increase the probability of receiving an acceptable job offer. Potential positive effects of taking up a mini-job during unemployment, for example by lowering human capital deterioration, as a screening device for potential employers or by increasing the job offer arrival rate due to network effects, seem to only occur if the marginal employment is related to sectoral experience and skills of the unemployed workers. This is in line with the descriptive evidence presented above, which shows that the sector of the mini-job positively correlates with both the sector of the previous job and the sector of the post-unemployment job. For the duration of employment we do not find any evidence for effect heterogeneity.

For the impact on the initial wage in a new job we find some evidence for effect heterogeneity. While the reference person - a skilled worker not working in the construction sector - takes up jobs with lower wages, this is neither the case for unskilled workers nor for workers in the construction sector. Moreover, the treated individuals enter higher paid jobs when the local unemployment rate is lower. These results indicate that good labour market conditions allow the treated unemployed workers to be more selective with respect to wages and job stability, while otherwise they end up in more stable jobs only. One reason for the difference with respect to the skill-level might be that mini-jobs are seen as a rather negative signal for skilled workers while this is not the case for unskilled individuals. A mini-job in the same sector as the previous job does not have an impact on the post-unemployment wage. 
In Table 9 we report the coefficients of the interaction effects of the treatment indicator with elapsed unemployment duration, allowing for different treatment effects in months 1-6, 7-12, 13-24 and 25-36. The results suggest a significantly positive effect of entering a mini-job after one year of unemployment, while we do not observe any significant impact on the probability of finding a job for the first 12 months (column 1). The effect in months 25-36 is positive but not statistically significant. However, the number of observations is decreasing over time and these estimates are based on a small number of unemployed individuals. These results suggest that there exist stepping stone effects of mini-jobs to regular jobs, but that these effects are only relevant for long-term unemployed workers.

\section{[INSERT TABle 9 ABOUt here]}

For employment stability we find a negative effect of having a mini-job on the probability of re-entering unemployment for regular jobs which are found during months 1-6 of the unemployment spell (column 2). These effects are stronger if the jobs are taken up after 12 months in the unemployment spell. In contrast to this, we do not find evidence for time-varying treatment effects on initial wages. None of the estimated coefficients are significantly different from zero (see column 3 ).

One important determinant of the probability of leaving unemployment for a job - the receipt of unemployment benefits - depends on the elapsed unemployment duration. The maximum duration of benefit receipt depends on the time spent in regular employment in the preceding years and the age at entry into unemployment, and after benefit exhaustion unemployed job-seekers are eligible for means-tested unemployment assistance (see Section 2 for details). Due to the reduced replacement rate for unemployment assistance the income during unemployment decreases over time. However, the rules for additional earnings from marginal employment do not change, and the decrease in income is rather small. This suggests that the exhaustion of benefits cannot explain the strong evidence for timevarying treatment effects of taking up marginal employment.

Given our descriptive evidence on a decreasing share of transitions within the same firm after twelve months of unemployment, the positive impact on employment stability is probably not driven by an increasing role of mini-jobs as a probation period. The results suggest that the positive effects of entering marginal employment - which might occur due to signaling effects, network effects, or the reduced deterioration of human capital - seem to lead to both an increase of the job-finding probability and the employment stability. These effects seem to be less relevant at the beginning of an unemployment spell, which is plausible given that the contact frequency with former colleagues (network) and the deterioration of human capital are probably time-dependent.

\subsection{Sensitivity Analysis}

We have estimated the model based on an alternative definition of unemployment. In contrast to our preferred specification, here we additionally define periods of our sample members which are not covered within the data as unemployment. This leads to longer unemployment spells and a higher number of treated individuals. Overall, we find very 
similar results for this alternative definition of unemployment (see Tables A.3 - A.5 in the Appendix).

In the baseline model the effect of entering a mini-job on the job-finding probability is significantly positive at the $5 \%$-level, which is probably driven by an increasing number of observations with longer unemployment durations. In line with this, we find stronger evidence for positive interaction effects of the treatment indicator with elapsed unemployment duration, see Table A.5. In this specification the treatment effect is significantly positive for unemployment durations between 25-36 months. Similar to the main specification, we only find evidence for effect heterogeneity for the unemployment duration with respect to the sector of the mini-job. We only observe an increased transition probability into regular employment if the mini-job is in the same sector as the previous regular job, whereby this effect is significant at the $10 \%$ level. Again, we do not find any evidence for effect heterogeneity with respect to employment stability. For the initial wages the effect for the construction sector is no longer significantly different from zero, while the significant effects for the skill level and the local unemployment rate are stable. Although we observe more transitions into regular employment especially for longer unemployment spells, again we do not find any evidence for different effects depending on the elapsed unemployment duration on initial wages.

We observe that individuals who take up marginal employment during unemployment have a higher probability of entering other measures of ALMP than unemployed individuals who do not enter a mini-job (see Section 3.3). In order to test whether our results are driven by the participation in other programs, we have re-estimated our model including time-varying indicators for the participation in ALMP. Our results do not change, which indicates that the impact of an increased participation in other ALMP measure cannot explain our results.

\section{Conclusion}

In some countries such as Germany and Austria unemployed workers are allowed to work for some hours during job search by taking up "marginal employment". Marginal employment is defined as employment below an income threshold with reduced social security contributions and job seekers can increase their income during unemployment up to a threshold without any benefit deduction. For unemployed individuals, income from marginal employment is fully exempted from pay-roll taxes, and for employers it is only subject to reduced pay-roll taxes. Although marginal employment does not legally belong within active labour market policy programs in Germany, it is comparable from an economic perspective to a wage subsidy. We analyze the causal impact of entering marginal employment on unemployment duration and job match quality of unemployed individuals and investigate potential effect heterogeneity with respect to observed characteristics and elapsed unemployment duration.

Based on a random inflow sample into unemployment of male workers in West Germany, our results suggest that the treatment effects vary according to the time spent in unemployment. While we do not find any significant impact for the first 12 months of 
unemployment, job-finding probabilities clearly increase after one year, and the impact on job stability is stronger for individuals who are unemployed for longer. We find a significantly positive impact on the transition probability to regular employment if the mini-job is in the same sector as the previous job. With regards to wages, we do not find any evidence for an interaction effect with elapsed unemployment duration. However, the impact on wages seems to vary with the skill level and the sector. Skilled individuals have a lower wage in the initial job after leaving unemployment if they had a mini-job. Moreover, the results indicate that the wage effects are increasing if the economic situation within the local labour market is more favourable.

Our descriptive analysis suggests that the positive impact on unemployment exit and employment stability especially for longer unemployed workers is probably not driven by an increasing role of mini-jobs as a probation period. It appears more plausible that mechanisms which might be less relevant at the beginning of an unemployment spell, like for example the deterioration of human capital and changing networks due to changing contact frequency with colleagues, could drive these effects. Moreover, marginal employment during unemployment seems to increase the job-finding probability particularly if the mini-job is related to the sectoral experience and skills of the unemployed workers. However, our analysis is based on administrative data and we do not have information about the search behavior of unemployed individuals with and without mini-jobs, nor on the changes in human capital over time. Future research should shed more light on the underlying mechanisms which might explain the positive effect of entering marginal employment on the employment outcomes.

Our results lead to the policy conclusion that - at least at the individual level mini-jobs can be an effective instrument to help long-term unemployed individuals to find (stable) jobs. Advantages of this instrument include that it does not involve any direct program costs, and that the administrative burden is low since the unemployed workers are searching for mini-jobs on their own. These findings are also highly relevant for the design and the timing of active labour market programs. As it is found that human capital deterioration and network effects become much more important with an increasing unemployment duration, the long-term unemployed should be primarily assigned to ALMP programs which have a strong link to the labour market, such as integration subsidies. Future research should shed some light on the interaction of marginal employment and measures such as job search assistance and training programs for unemployed workers. However, having a mini-job does not seem to have the same effect for all groups, and the results suggest the instrument does not help to increase the job finding probabilities at the beginning of an unemployment spells. 


\section{References}

Abbring, J., And G. VAN DEN Berg (2003): "The Non-Parametric Identification of Treatment Effects in Duration Models,," Econometrica, 71, 1491-1517.

Aitkin, M. (1999): "A General Maximum Likelihood Analysis of Variance Components in Generalized Linear Models," Biometrics, 55(1), 117-128.

Arni, P., R. Lalive, and J. C. van Ours (2012): "How Effective Are Unemployment Benefit Sanctions? Looking Beyond Unemployment Exit," Journal of Applied Econometrics, forthcoming.

Belzil, C. (2001): "Unemployment Insurance and Subsequent Job Duration: Job Matching vs Unobserved Heterogeneity," Journal of Applied Econometrics, 16, 619-636.

BöHeim, R., ANd A. Weber (2011): "The Effects of Marginal Employment on Subsequent Labour Market Outcomes," German Economic Review, 12, 165-181.

Caliendo, M., A. Falk, L. Kaiser, H. Schneider, A. Uhlendorff, G. van den Berg, And K. Zimmermann (2011): "The IZA Evaluation Dataset," International Journal of Manpower, 32(7), 731-752.

Caliendo, M., K. Tatsiramos, and A. Uhlendorff (2009): "Benefit Duration, Unemployment Duration and Job Match Quality: A Regression-Discontinuity Approach," IZA Discussion Paper, 4750.

Caliendo, M., and K. Wrohlich (2010): "Evaluating the German 'Mini-Job' Reform Using a Natural Experiment," Applied Economics, 42, 2475-2489.

Card, D., R. Chetty, and A. Weber (2007): "Cash-On-Hand and competing Models of Intertemporal Behavior: New Evidence from the Labor Market," Quarterly Journal of Economics, 122, 1511-1560.

Card, D., J. Kluve, And A. Weber (2010): "Active Labor Market Policy Evaluations: A Meta-analysis," Economic Journal, 120, 452-477.

Cockx, B., And M. Picchio (2011): "Are Short-Term Jobs Springboards to Long-Term Jobs? A New Approach," Oxford Bulletin of Economics and Statistics, forthcoming.

Crepon, B., M. Ferracci, G. Jolivet, and G. J. van den Berg (2010): "Analyzing the Anticipation of Treatments Using Data on Notification Dates," IZA Discussion Paper, 5265.

Eberwein, C., J. Ham, and R. LaLonde (1997): "The impact of being offered and receiving classroom training on the employment histories of disadvantaged women: Evidence from experimental data," Review of Economic Studies, 64, 655-682.

Freier, R., And V. Steiner (2008): “'Marginal Employment': Stepping Stone or Dead End? Evaluating the German Experience," Zeitschrift für Arbeitsmarktforschung, 41(2/3), 223-243.

Gaure, S., K. Roed, and T. Zhang (2007): "Time and Causality: A Monte Carlo Assesment of the timing-of-events approach," Journal of Econometrics, 141, 1159-1195.

HaAn, P. (2010): "A Multi-state Model of State Dependence in Labor Supply: Intertemporal Labor Supply Effects of a Shift from Joint to Individual Taxation," Labour Economics, 17, 323-335. 
Heckman, J. J. (1981): "The Incedental Paramter Problem and the Problem of Initial Conditions in Estimating a Discrete Time-Discrete Data Stochastic Process," in Structural Analysis of Discrete Data with Econometric Applications, ed. by C. Manski, and D.McFadden, pp. 179-195. MIT Press, Cambridge, MA.

Heckman, J. J., and S. Navarro (2007): "Dynamic Discrete Choice and Dynamic Treatment Effects," Journal of Econometrics, 136, 341-396.

Honore, B. (1993): "Identification Results for Duration Models with Multiple Spells,"

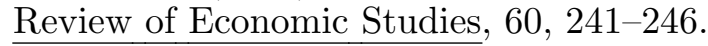

KLuve, J. (2010): "The Effectiveness of European Active Labor Market Programs," Labour Economics, 16, 904-918.

Konle-Seidl, R., W. Eichhorst, and M. Grienberger-Zingerle (2010): "Activation Policies in Germany: From Status Protection to Basic Income Support," German Policy Studies, 6, 59-100.

KYyRÄ, T. (2010): "Partial unemployment insurance benefits and the transition rate to regular work," European Economic Review, 54, 911-930.

Kyyrä, T., P. Parrotta, and M. Rosholm (2009): "The Effect of Receiving Supplementary UI Benefits on Unemployment Duration," IZA Discussion-Paper, 3920.

Rudolph, H. (1999): "Das 630-DM-Gesetz: Was ändert sich für wen?," IAB-Kurzbericht, 11.

Tatsiramos, K. (2009): "Unemployment Insurance in Europe: Unemployment Duration and Subsequent Employment Stability," Journal of the European Economic Association, 7, 1225-1260.

VAn den Berg, G., And J. Vikström (2009): "Monitoring Job Offer Decisions, Punishments, Exit to Work, and Job Quality," IZA Discussion-Paper, 4325.

van den Berg, G. J., A. Holm, and J. C. van Ours (2002): "Do stepping-stone jobs exist? Early career paths in the medical profession," Journal of Population Economics, 15, 647-655.

VAN OuRs, J. C., ANd M. Vodopivec (2008): "Does reducing unemployment insurance generosity reduce job match quality?," Journal of Public Economics, 92, 684-695.

ZiJl, M., G. J. van den Berg, and A. Heyma (2011): "Stepping Stones for the Unemployed: The Effect of Temporary Jobs on the Duration until Regular Work," Journal of Population Economics, 24, 107-139. 


\section{Tables}

Table 1: Spells per person

\begin{tabular}{lrrr}
\hline \hline $\begin{array}{l}\text { Number } \\
\text { of Spells }\end{array}$ & Unemployment & $\begin{array}{c}\text { Mini-Job } \\
\text { (while being UE) }\end{array}$ & Employment \\
\hline 0 & - & 8,493 & 2,919 \\
1 & 5,516 & 1,337 & 3,931 \\
2 & 2,415 & 137 & 1,595 \\
3 & 1,574 & $33^{a)}$ & 1,362 \\
4 & 413 & $\star$ & 149 \\
$\geq 5$ & 82 & $\star$ & 44 \\
\hline \hline
\end{tabular}

Note: Depicted are the number of spells per person. For instance, 5,516 individuals have only one single unemployment spell while 82 individuals have five or more. Each column sums up to the total number of individuals $(\mathrm{N}=10,000)$.

a) Contains the number of individuals with three or more mini-job spells.

* To secure data anonymity cells with less than 20 observations are not shown. 
Table 2: Descriptive statistics of observed characteristics

\begin{tabular}{|c|c|c|c|c|}
\hline & \multirow{3}{*}{$\begin{array}{c}\text { Full } \\
\text { sample }\end{array}$} & \multicolumn{3}{|c|}{ Estimation sample } \\
\hline & & \multirow[t]{2}{*}{ All } & \multicolumn{2}{|c|}{ Having a Mini-Job } \\
\hline & & & No & Yes \\
\hline Number of individuals & 24,131 & 10,000 & 8,493 & 1,507 \\
\hline Age (in years) & $\begin{array}{c}37.4 \\
(8.1)\end{array}$ & $\begin{array}{c}37.4 \\
(8.2)\end{array}$ & $\begin{array}{r}37.5 \\
(8.1)\end{array}$ & $\begin{array}{c}37.2 \\
(8.2)\end{array}$ \\
\hline Married & 52.9 & 52.5 & 52.2 & 54.2 \\
\hline Children & 33.6 & 33.2 & 32.9 & 35.0 \\
\hline Children $\leq 10$ years & 22.0 & 21.5 & 21.2 & 23.2 \\
\hline Non-German & 15.7 & 15.7 & 14.6 & 21.6 \\
\hline Severely handicapped & 2.0 & 2.1 & 2.2 & 1.5 \\
\hline Health restrictions & 12.5 & 12.4 & 12.0 & 14.8 \\
\hline \multicolumn{5}{|l|}{ School leaving certificate } \\
\hline No degree & 9.4 & 9.5 & 8.8 & 13.5 \\
\hline Lower secondary school & 59.5 & 59.6 & 58.9 & 63.7 \\
\hline Middle secondary school & 15.5 & 15.7 & 15.7 & 15.3 \\
\hline (Specialized) Upper secondary school & 15.6 & 15.2 & 16.6 & 7.5 \\
\hline \multicolumn{5}{|l|}{ Professional training } \\
\hline Unskilled & 30.3 & 30.1 & 28.1 & 41.5 \\
\hline Apprenticeship or technical college degree & 63.2 & 63.6 & 65.0 & 55.6 \\
\hline University degree & 6.5 & 6.3 & 6.9 & 2.9 \\
\hline \multicolumn{5}{|l|}{ Sector of last job } \\
\hline Construction & 25.4 & 25.8 & 26.3 & 23.1 \\
\hline Production & 21.7 & 21.3 & 21.3 & 21.3 \\
\hline Wholesale/Retail & 13.1 & 13.0 & 13.0 & 12.9 \\
\hline Private sector services & 26.6 & 26.6 & 25.9 & 30.8 \\
\hline Others (public sector, agriculture) & 13.2 & 13.3 & 13.5 & 11.9 \\
\hline \multicolumn{5}{|l|}{ Local macroeconomic conditions } \\
\hline Unemployment rate (in \%) & $\begin{array}{r}7.6 \\
(2.4)\end{array}$ & $\begin{array}{r}7.6 \\
(2.4)\end{array}$ & $\begin{array}{r}7.5 \\
(2.4)\end{array}$ & $\begin{array}{r}8.0 \\
(2.3)\end{array}$ \\
\hline Real GDP per capita $\left.{ }^{a}\right)$ (in thousand $€$ ) & $\begin{array}{r}28.6 \\
(11.5)\end{array}$ & $\begin{array}{r}28.6 \\
(11.5)\end{array}$ & $\begin{array}{r}28.7 \\
(11.7)\end{array}$ & $\begin{array}{r}28.2 \\
(10.6)\end{array}$ \\
\hline
\end{tabular}

Note: All statistics are percentages (if not differently indicated) and measured at entry into unemployment; standard deviations in parenthesis.

a) Normalized to prices in 2005 .

Table 3: Sectoral distribution of mini-jobs

\begin{tabular}{|c|c|c|c|}
\hline & \multirow[t]{2}{*}{ All } & \multicolumn{2}{|c|}{ Professional training background } \\
\hline & & Unskilled & Skilled \\
\hline Number of spells & 1,713 & 698 & 1,015 \\
\hline Construction & 21.3 & 21.3 & 21.3 \\
\hline Production & 8.3 & 7.3 & 9.1 \\
\hline Wholesale/Retail & 14.0 & 11.6 & 15.7 \\
\hline Private sector services & 45.1 & 50.4 & 41.4 \\
\hline Others (public sector, agriculture) & 11.3 & 9.3 & 12.6 \\
\hline
\end{tabular}

Note: All statistics are percentages (if not differently indicated). Individuals who have no professional degree at entry into unemployment are categorized as "unskilled" and as "skilled" otherwise. 
Table 4: Sectoral transition matrix: From previous job to mini-job

\begin{tabular}{|c|c|c|c|c|c|}
\hline \multirow[t]{2}{*}{ Sector of previous job } & \multicolumn{5}{|c|}{ Sector of mini-job } \\
\hline & Constr. & Prod. & Retail & Services & Others \\
\hline Construction & 75.2 & $\star$ & $\star$ & 13.7 & 夫 \\
\hline Production & 18.3 & 28.1 & 17.0 & 31.4 & * \\
\hline Wholesale/Retail & $\star$ & $\star$ & 35.6 & 42.3 & * \\
\hline Private sector services & $\star$ & $\star$ & 9.8 & 76.1 & * \\
\hline Others (public sector, agriculture) & $\star$ & $\star$ & $\star$ & 25.3 & 54.5 \\
\hline
\end{tabular}

Note: Depicted is the sectoral distribution of mini-jobs during unemployment conditional on the sector of the previous jobs; all statistics are in percentages (if not differently indicated). In total, we observe 911 mini-jobs. For instance, among all treated individuals who previously worked in the construction sector, $75.2 \%$ also take up a mini-job in the same sector.

$\star$ To secure data anonymity cells with less than 20 observations are not shown.

Table 5: Sectoral transition matrix: From mini-job to subsequent job

\begin{tabular}{lrrrrr}
\hline \hline \multirow{2}{*}{ Sector of mini-job } & \multicolumn{5}{c}{ Sector of subsequent job } \\
& Constr. & Prod. & Retail & Services & Others \\
\hline Construction & 82.4 & 8.0 & $\star$ & $\star$ & $\star$ \\
Production & $\star$ & 62.8 & $\star$ & $\star$ & $\star$ \\
Wholesale/Retail & $\star$ & $\star$ & 42.5 & 34.9 & $\star$ \\
Private sector services & 8.1 & 9.4 & 8.4 & 68.7 & 5.4 \\
Others (public sector, agriculture) & $\star$ & $\star$ & $\star$ & 26.3 & 58.9 \\
& & & & & \\
\hline \hline
\end{tabular}

Note: Depicted is the sectoral distribution of subsequent jobs conditional on the sector of the mini-job during unemployment; all statistics are in percentages (if not differently indicated). In total, we observe 911 transitions. For instance, out of all unemployed individuals who have a mini-job in the construction sector, $82.4 \%$ also find regular employment in the same sector.

* To secure data anonymity cells with less than 20 observations are not shown.

Table 6: Transition from UE (with mini-job) to RE within same firm

\begin{tabular}{crrr}
\hline \hline & All & \multicolumn{2}{c}{ Timing of transition to employment } \\
& & & \\
& & 612 months & $>12$ months \\
\hline All transition to RE & 911 & 52.0 & 294 \\
Within same firm (in \%) & 45.0 & 395 & 30.3 \\
Direct transition to RE & 484 & 60.0 & 39.3 \\
Within same firm (in \%) & 56.2 & & \\
\hline \hline
\end{tabular}

Note: Depicted is the share of treated transitions from unemployment to employment which take place within the same firm, i.e., the mini-job during unemployment and the subsequent regular job are within the same firm. UE - Unemployment, RE - Regular employment. 
Table 7: Baseline estimation results

\begin{tabular}{|c|c|c|c|c|c|c|}
\hline & \multicolumn{2}{|c|}{ Transition UE to RE } & \multicolumn{2}{|c|}{ Transition RE to UE } & \multicolumn{2}{|c|}{ Linear wage equation } \\
\hline & (1) & $(2)$ & $(3)$ & (4) & (5) & $(6)$ \\
\hline Mini-Job & $\begin{array}{l}0.129^{* * *} \\
(0.037)\end{array}$ & $\begin{array}{c}0.030 \\
(0.049)\end{array}$ & $\begin{array}{c}0.007 \\
(0.045)\end{array}$ & $\begin{array}{c}-0.277^{* * *} \\
(0.065)\end{array}$ & $\begin{array}{c}-0.074^{* * *} \\
(0.010)\end{array}$ & $\begin{array}{c}-0.002 \\
(0.009)\end{array}$ \\
\hline Unobs. Het. $(\mathrm{P}=9)$ & No & Yes & No & Yes & No & Yes \\
\hline
\end{tabular}

Table 8: Treatment effect heterogeneity with respect to observed characteristics

\begin{tabular}{lccc}
\hline \hline & $\begin{array}{c}\text { Transition } \\
\text { UE to RE } \\
(1)\end{array}$ & $\begin{array}{c}\text { Transition } \\
\text { RE to UE }\end{array}$ & $\begin{array}{c}\text { Linear wage } \\
\text { equation } \\
(3)\end{array}$ \\
\hline Mini-Job & -0.088 & $-0.398^{* * *}$ & $-0.027^{* *}$ \\
& $(0.076)$ & $(0.101)$ & $(0.013)$ \\
Mini-Job $\times$ Ln(Age) & -0.149 & -0.031 & 0.038 \\
Mini-Job $\times$ Unskilled & $(0.187)$ & $(0.248)$ & $(0.036)$ \\
& 0.016 & -0.016 & $0.037^{* * *}$ \\
Mini-Job $\times$ Construction & $(0.081)$ & $(0.102)$ & $(0.014)$ \\
Mini-Job $\times$ Local UE-Rate & -0.009 & 0.163 & $0.035^{* *}$ \\
Mini-Job $\times$ Same Sector & $(0.085)$ & $(0.120)$ & $(0.015)$ \\
& $(0.013$ & -0.024 & $-0.007^{* *}$ \\
Unobs. Het. (P=9) & $0.172^{* * *}$ & $(0.020)$ & $(0.003)$ \\
& $(0.078)$ & 0.127 & 0.000 \\
& Yes & $(0.100)$ & $(0.014)$ \\
\hline \hline
\end{tabular}

Note: Coefficients are statistically significant at the ${ }^{*} 10 \%,{ }^{* *} 5 \%,{ }^{* * *} 1 \%$ level. The estimation also includes control variables for duration dependence, seasonal dummies, individual socio-demographics, information on last job and local macroeconomic conditions. Individuals who have no professional degree at entry into unemployment are categorized as "unskilled". "Same sector" indicates that the mini-job was taken up within the same sector (construction, production, wholesale/retail, private sector services, others) as the last regular job. The reference person is an individual of mean age located in a region with the mean local unemployment rate, not working in the construction sector and not being unskilled. UE - Unemployment, RE - Regular employment. 
Table 9: Treatment effect heterogeneity with respect to elapsed unemployment duration

\begin{tabular}{lccc}
\hline \hline & $\begin{array}{c}\text { Transition UE to RE } \\
(1)\end{array}$ & $\begin{array}{c}\text { Transition RE to UE } \\
(2)\end{array}$ & $\begin{array}{c}\text { Linear wage equation } \\
(3)\end{array}$ \\
\hline Mini-Job & -0.096 & $-0.153^{*}$ & -0.011 \\
& $(0.066)$ & $(0.085)$ & $(0.012)$ \\
Mini-Job $\times 7$-12 months & 0.125 & -0.133 & 0.027 \\
& $(0.096)$ & $(0.119)$ & $(0.017)$ \\
Mini-Job $\times 13-24$ months & $0.405^{* * *}$ & $-0.425^{* * *}$ & $(0.019)$ \\
Mini-Job $\times 25-36$ months & $(0.101)$ & $(0.136)$ & -0.007 \\
& 0.168 & 0.153 & $(0.032)$ \\
Unobs. Het. $(\mathrm{P}=9)$ & $(0.141)$ & $(0.270)$ & Yes \\
\hline \hline
\end{tabular}

Note: Coefficients are statistically significant at the * $10 \%, * * 5 \%, * * * 1 \%$ level. The estimation also includes control variables for duration dependence, seasonal dummies, individual socio-demographics, information on last job and local macroeconomic conditions. UE - Unemployment, RE - Regular employment. 


\section{Figures}

Figure 1: Hazard functions
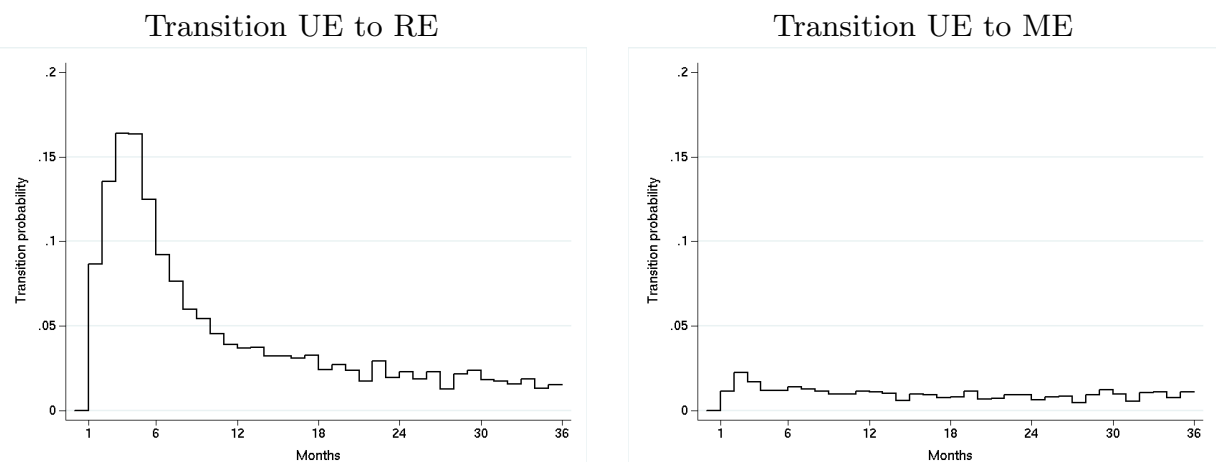

Note: Depicted are unconditional transitions probabilities. UE - Unemployment, ME - Marginal employment, RE - Regular employment.

Figure 2: Income distribution of mini-jobs during unemployment

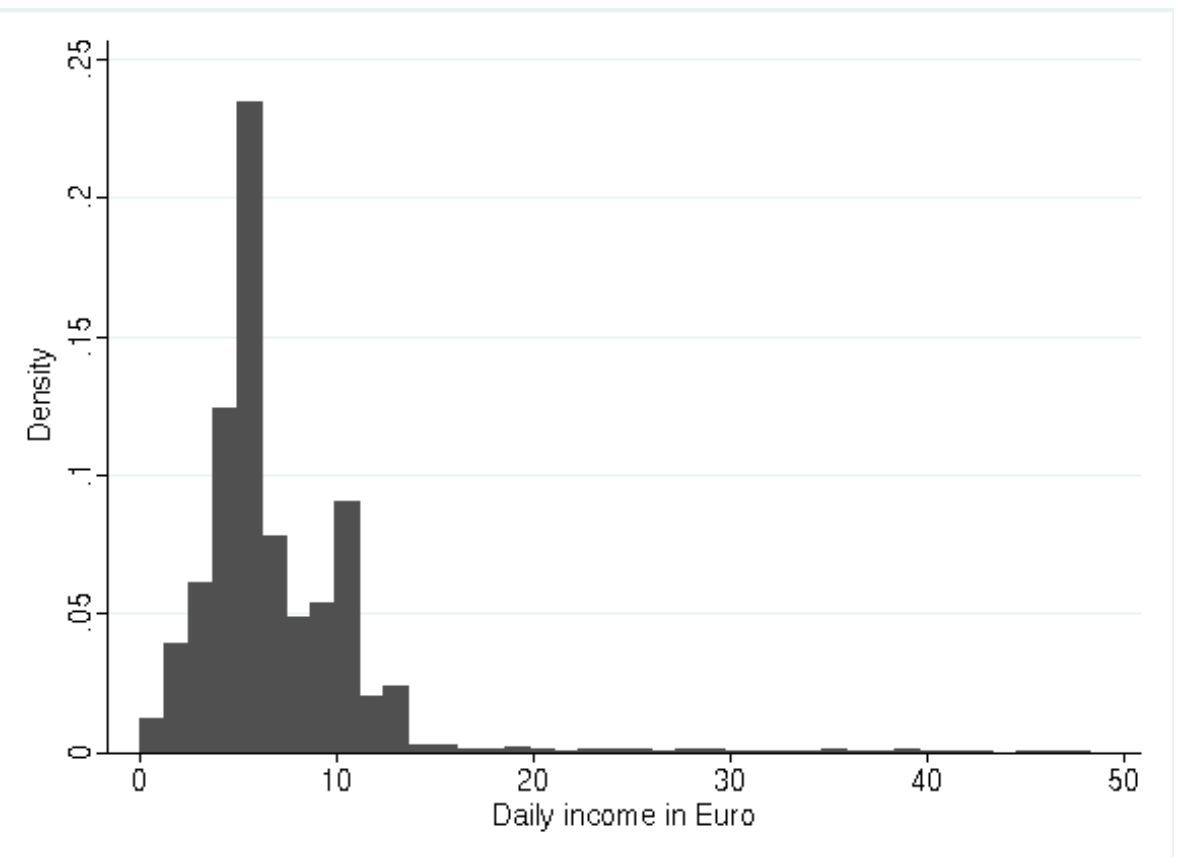

Note: The mean and median of the income distribution amount to 6.9 and 5.4 Euro respectively; whereby these daily incomes correspond to 207 and 164 Euro per months. 


\section{A Appendix}

Table A.1: First transition to ALMP or minijob during first/initial unemployment spell within the estimation sample

\begin{tabular}{|c|c|c|}
\hline & \multicolumn{2}{|c|}{ All } \\
\hline Number of individuals & \multicolumn{2}{|c|}{10,000} \\
\hline \multicolumn{3}{|c|}{ First transition to programs of ALMP } \\
\hline Job creation Schemes & \multicolumn{2}{|c|}{0.6} \\
\hline Wage subsidy & \multicolumn{2}{|c|}{3.4} \\
\hline Promotion of start-ups & \multicolumn{2}{|c|}{4.9} \\
\hline Vocational training & \multicolumn{2}{|c|}{4.9} \\
\hline Short-term training & \multicolumn{2}{|c|}{9.3} \\
\hline Other programs & \multicolumn{2}{|c|}{1.6} \\
\hline First transition to mini-job & \multicolumn{2}{|c|}{7.2} \\
\hline & \multicolumn{2}{|c|}{$\begin{array}{l}\text { Having a Mini-Job } \\
\text { during first UE spell }\end{array}$} \\
\hline & No & Yes \\
\hline Number of individuals & 9,066 & 934 \\
\hline \multicolumn{3}{|c|}{ First transition to programs of ALMP } \\
\hline Job creation Schemes & 0.6 & $\star$ \\
\hline Wage subsidy & 3.4 & 6.9 \\
\hline Promotion of start-ups & 5.2 & 4.7 \\
\hline Vocational training & 4.9 & 9.7 \\
\hline Short-term training & 9.2 & 20.3 \\
\hline Other programs & 1.6 & 2.5 \\
\hline
\end{tabular}

Note: Only the first unemployment spell is considered which explains the divergent number of observations compared to Table 1 and 2. All statistics are percentages (if not differently indicated). For instance, $3.4 \%$ received a wage subsidy as the first treatment while $7.2 \%$ entered a mini-job. UE - Unemployment, ALMP - Active labor market policy.

* To secure data anonymity cells with less than 20 observations are not shown.

Table A.2: Estimated correlations between unobserved terms

\begin{tabular}{lrr}
\hline \hline & \multicolumn{2}{c}{$\mathrm{P}=9$} \\
\hline $\operatorname{Corr}\left(V_{u}, V_{m}\right)$ & $0.302^{* * *}$ & $(0.117)$ \\
$\operatorname{Corr}\left(V_{u}, V_{e}\right)$ & $0.232^{*}$ & $(0.122)$ \\
$\operatorname{Corr}\left(V_{u}, V_{w}\right)$ & $0.410^{* * *}$ & $(0.039)$ \\
$\operatorname{Corr}\left(V_{m}, V_{e}\right)$ & $0.579^{* * *}$ & $(0.145)$ \\
$\operatorname{Cor}\left(V_{m}, V_{w}\right)$ & $-0.390^{* * *}$ & $(0.062)$ \\
$\operatorname{Corr}\left(V_{e}, V_{w}\right)$ & $-0.262^{* * *}$ & $(0.033)$ \\
\end{tabular}

Note: Correlations are statistically significant at the $* 10 \%, * * 5 \%, * * * 1 \%$ level. 
Table A.3: Alternative definition of unemployment: Baseline estimation results

\begin{tabular}{llccccc}
\hline \hline & \multicolumn{3}{c}{ Transition UE to RE } & \multicolumn{2}{c}{ Transition RE to UE } & \multicolumn{2}{c}{ Linear wage equation } \\
& $(1)$ & $(2)$ & $(3)$ & $(4)$ & $(5)$ & $(6)$ \\
\hline Mini-Job & $0.178^{* * *}$ & $0.100^{* *}$ & -0.001 & $-0.188^{* * *}$ & $-0.074^{* * *}$ & 0.002 \\
& $(0.034)$ & $(0.047)$ & $(0.041)$ & $(0.062)$ & $(0.009)$ & $(0.009)$ \\
Unobs. Het. $(\mathrm{P}=9)$ & No & Yes & No & Yes & No & Yes \\
\hline \hline
\end{tabular}

Note: Depicted are estimation results using an alternative definition of unemployment. In contrast to the preferred specification (see Table 7), here we additionally define periods not covered by the data as unemployment. Coefficients are statistically significant at the $* 10 \%, * * 5 \%, * * * 1 \%$ level. The estimation also includes control variables for duration dependence, seasonal dummies, individual socio-demographics, information on last job and local macroeconomic conditions. UE - Unemployment, RE - Regular employment.

Table A.4: Alternative definition of unemployment: Effect heterogeneity

\begin{tabular}{lccc}
\hline \hline & Transition & Transition & Linear wage \\
UE to RE & RE to UE & $(2)$ & $(3)$ \\
& $(1)$ & $-0.289^{* * *}$ & $-0.023^{*}$ \\
Mini-Job & 0.017 & $(0.092)$ & $(0.014)$ \\
& $(0.072)$ & -0.111 & 0.057 \\
Mini-Job $\times$ Ln(Age) & -0.090 & $(0.215)$ & $(0.038)$ \\
Mini-Job $\times$ Unskilled & $(0.172)$ & -0.012 & $0.049^{* * *}$ \\
Mini-Job $\times$ Construction & 0.048 & $(0.090)$ & $(0.015)$ \\
Mini-Job $\times$ Local UE-Rate & $(0.076)$ & 0.059 & 0.024 \\
Mini-Job $\times$ Same Sector & -0.069 & $(0.101)$ & $(0.016)$ \\
& $(0.081)$ & -0.024 & $-0.006^{* *}$ \\
Unobs. Het. (P=9) & $0.133^{*}$ & $0.017)$ & $(0.003)$ \\
& $(0.073)$ & $(0.087)$ & $(0.006)$ \\
\hline \hline
\end{tabular}

Note: Depicted are estimation results using an alternative definition of unemployment. In contrast to the preferred specification (see Table 8), here we additionally define periods not covered by the data as unemployment. Coefficients are statistically significant at the * $10 \%, * * 5 \%, * * * 1 \%$ level. The estimation also includes control variables for duration dependence, seasonal dummies, individual socio-demographics, information on last job and local macroeconomic conditions. Individuals who have no professional degree at entry into unemployment are categorized as "unskilled". "Same sector" indicates that the mini-job was taken up within the same sector (construction, production, wholesale/retail, private sector services, others) as the last regular job. UE - Unemployment, RE - Regular employment. 
Table A.5: Alternative definition of unemployment: Treatment effect and elapsed unemployment duration

Transition UE to RE Transition RE to UE Linear wage equation (1)

\begin{tabular}{lccc}
\hline Mini-Job & -0.074 & $-0.138^{*}$ & -0.006 \\
& $(0.064)$ & $(0.083)$ & $(0.013)$ \\
Mini-Job $\times 7$-12 months & $0.161^{*}$ & -0.067 & 0.021 \\
& $(0.091)$ & $(0.106)$ & $(0.018)$ \\
Mini-Job $\times 13-24$ months & $0.562^{* * *}$ & $-0.251^{* *}$ & 0.024 \\
& $(0.094)$ & $(0.117)$ & $(0.018)$ \\
Mini-Job $\times 25-36$ months & $0.326^{* * *}$ & 0.225 & -0.013 \\
& $(0.125)$ & $(0.210)$ & $(0.031)$ \\
Unobs. Het. $(\mathrm{P}=9)$ & Yes & Yes & Yes \\
\hline
\end{tabular}

Note: Depicted are estimation results using an alternative definition of unemployment. In contrast to the preferred specification (see Table 9), here we additionally define periods not covered by the data as unemployment. Coefficients are statistically significant at the $* 10 \%, * * 5 \%, * * * 1 \%$ level. The estimation also includes control variables for duration dependence, seasonal dummies, individual socio-demographics, information on last job and local macroeconomic conditions. UE - Unemployment, RE - Regular employment. 